$06 ; 11 ; 13$

\title{
Влияние поверхностной нейтрализации активной примеси на автоэмиссионные свойства кристаллов кремния $p$-типа
}

\author{
(C) P.K. Яфраров
}

Саратовский фрилиал Института радиотехники и электроники им. В.А. Котельникова РАН

E-mail: pirpc@yandex.ru

Поступило в Редакцию 28 июня 2017 г.

Исследованы корреляционные закономерности изменений структурнофазового состава, морфологических и автоэмиссионных характеристик поверхностно структурированных кремниевых пластин дырочного типа проводимости ориентации (100) при их ступенчатой высокодозной ионно-лучевой обработке углеродом. Показано, что ступенчатая имплантация уменьшает пороги автоэмиссии и способствует увеличению максимальных плотностей автоэмиссионных токов более чем на два порядка. Рассмотрены физико-химические механизмы, ответственные за модификацию приповерхностных свойств кремниевых структур при ионной имплантации углерода.

DOI: 10.21883/PJTF.2017.24.45346.16937

Недостатками полевых источников электронов на основе кремния являются высокая чувствительность к состоянию поверхности и низкие плотности автоэмиссионных токов, которые, как правило, находятся в интервале $50-150 \mu \mathrm{A} / \mathrm{cm}^{2}$ [1]. Такие плотности токов удовлетворяют требованиям использования чисто кремниевых автоэмиссионных катодов в области FED (field emission displays - дисплеев с полевыми эмиттерами). Однако этого не достаточно для создания, например, вакуумных полевых транзисторов с высокой выходной мощностью. Большой интерес вызывают также исследования, направленные на создание фотополевых детекторов на основе кремния $p$-типа, квантовая эффективность которых может существенно превышать 100\% и которые могут успешно работать в инфракрасной области спектра, а также вакуумных транзисторов и светодиодов, которые по теоретическим оценкам могут работать на терагерцевых частотах [2]. 
Перспективным направлением исследований по созданию сильноточных источников электронов является получение катодных матриц путем имплантации ионов углерода в кремниевые подложки. Облучение ионами с различными энергиями, при которых модифицируются свойства подложки на разных глубинах, дает возможность гибко управлять распределением в ней фазовых составов и связанными с ними электрофизическими свойствами.

Цель настоящей работы - исследовать влияние структурирования поверхности и ступенчатой высокодозной ионно-лучевой обработки углеродом приповерхностных областей пластин $\mathrm{Si}$ (100) дырочного типа проводимости на их автоэмиссионные свойства.

Структурирование поверхности кремния осуществлялось путем осаждения островковых углеродных масочных покрытий в микроволновой плазме паров этанола на кристаллы кремния КДБ $(0.01-0.02)$ с естественным оксидным покрытием с последующим высокоанизотропным плазмохимическим травлением в плазме хладона-14 по методике, изложенной в [3]. Имплантация проводилась на установке с импульсным источником ионов „Радуга-3М“. После базового высокодозного облучения однозарядными ионами $\mathrm{C}^{+}$с дозой $1 \cdot 10^{18} \mathrm{~cm}^{-2}$ и энергией $80 \mathrm{keV}$ поверхностно-структурированных кристаллов кремния часть из них подвергалась дополнительной ионной имплантации углеродом с энергией $30 \mathrm{keV}$ при дозе $5 \cdot 10^{17} \mathrm{~cm}^{-2}$. Для анализа морфологии и фазового состава ионно-имплантированных кремниевых пластин были использованы методы атомно-силовой и конфокальной рамановской микроскопии/спектроскопии. Исследования автоэмиссионных свойств осуществлялись в условиях высокого вакуума $\left(10^{-6} \mathrm{~Pa}\right)$ на диодной структуре, способной изменять расстояние между электродами с точностью до $1 \mu \mathrm{m}$.

На рис. 1 приведены спектры рамановского рассеяния кристаллов кремния, облученных ионами $\mathrm{C}^{+}$с различными дозами при $80 \mathrm{keV}$, до и после дополнительного облучения с дозой $5 \cdot 10^{17} \mathrm{~cm}^{-2}$ при $30 \mathrm{keV}$. После базовой и дополнительной имплантации в спектрах рамановского рассеяния проявляются широкие линии, которые представлены аморфными фазами кремния (полоса рассеяния с максимумом при $480 \mathrm{~cm}^{-1}$ ), углерода (полосы $G$ (при $1350 \mathrm{~cm}^{-1}$ ) и $D$ (при $1585 \mathrm{~cm}^{-1}$ ) рамановского рассеяния на $s p^{2}$ - и $s p^{3}$-связях в аморфном углероде), а также карбида кремния (полоса рассеяния при $740 \mathrm{~cm}^{-1}$ ). С увеличением дозы имплантированных ионов уменьшается доля аморфного кремния

Письма в ЖТФ, 2017, том 43, вып. 24 


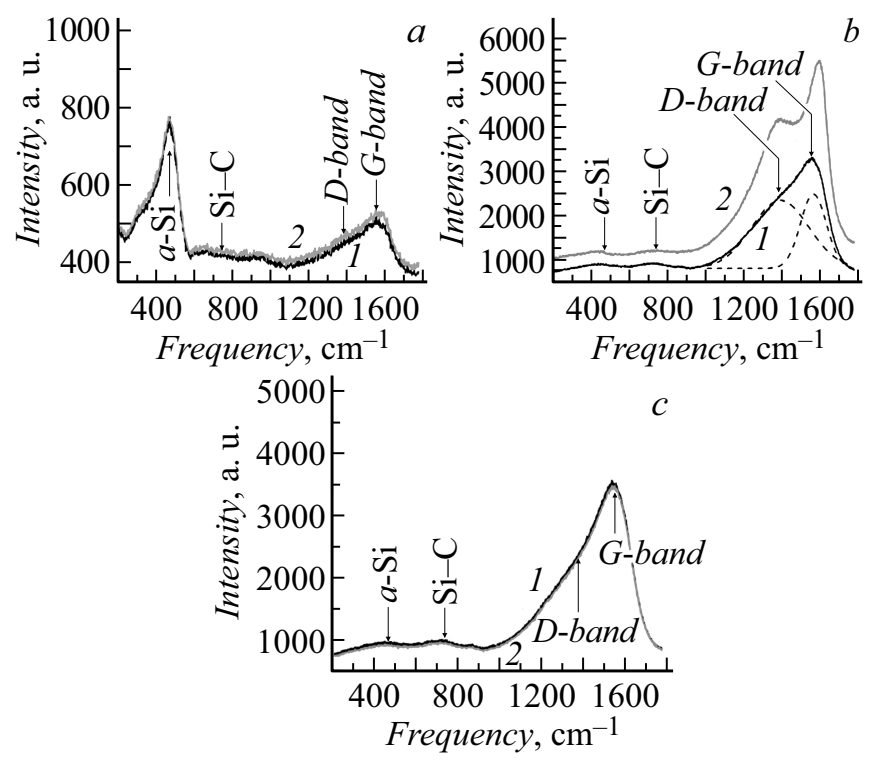

Рис. 1. Спектры рамановского рассеяния образцов кремния, облученных ионами $\mathrm{C}^{+}$с дозами $1 \cdot 10^{17}(a), 1 \cdot 10^{18} \mathrm{~cm}^{-2}(b, c)$ при $80 \mathrm{keV}$, до $(a, b)$ и после $(c)$ дополнительного облучения с дозой $5 \cdot 10^{17} \mathrm{~cm}^{-2}$ при $30 \mathrm{keV}$. Различные кривые соответствуют разным точкам поверхности: 1 - вне выступа; 2 - в выступе. Штриховыми линиями показано разложение одного экспериментального спектра на гауссовы линии.

и увеличивается доля углеродных фаз преимущественно за счет образования фаз алмазоподобного углерода. Изменения фазового состава более интенсивно происходят в выступах на поверхности кремния (рис. 1, $a, b)$.

На рис. 2 приведены зависимости от дозы облучения ионами углерода с энергией $80 \mathrm{keV}$ максимальных плотностей токов полевой эмиссии электронов, полученные в стационарном режиме измерения на исходных (безострийных - „гладких ${ }^{6}$ ) и поверхностно-структурированных с использованием островковых углеродных покрытий пластинах кремния $p$-типа. При дозе $1 \cdot 10^{18} \mathrm{~cm}^{-2}$ для пластин со структурированной поверхностью увеличение максимальной плотности тока по сравнению

Письма в ЖТФ, 2017, том 43, вып. 24 


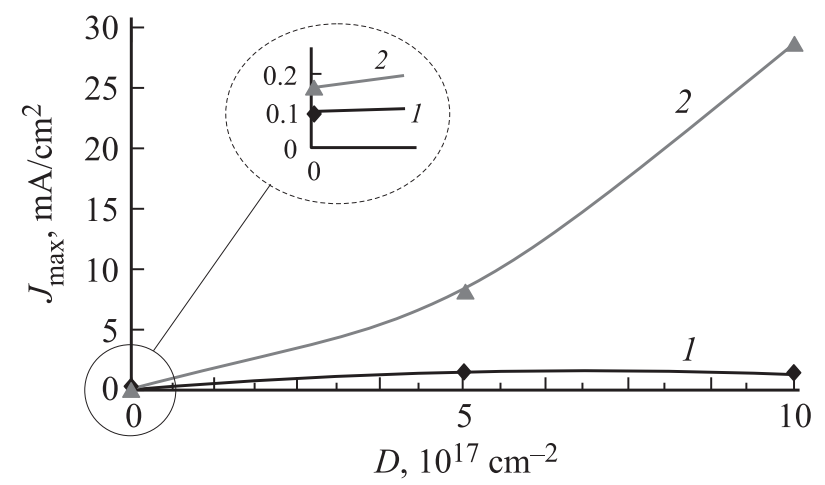

Рис. 2. Зависимости от дозы облучения ионами $\mathrm{C}^{+}$максимальных плотностей токов полевой эмиссии электронов на исходных („гладких“) (1) и поверхностно-структурированных (2) пластинах кремния (100) p-типа. На вставке - значения максимальных плотностей автоэмиссионных токов на „гладких“ (1) и поверхностно-структурированных (2) пластинах кремния в отсутствие облучения.

с таковой для облученных ионами углерода с той же дозой кристаллов кремния с неструктурированной поверхностью составляет более одного, а по сравнению с величиной для необлученных кристаллов кремния более двух порядков величины.

При дополнительном ионном облучении формы рамановских спектров изменяются, а общее количество углеродных фаз продолжает увеличиваться (рис $1, c$ ). Для получения количественной зависимости соотношения $s p^{3}$ - и $s p^{2}$-связей от дозы углерода проведено разложение „углеродной“ полосы рамановского рассеяния в диапазоне частот $1000-1700 \mathrm{~cm}^{-1}$ на гауссовы компоненты, соответствующие полосам $G$ и $D$. Относительный вклад полос $G$ и $D$ определялся исходя из соотношения их интегральных интенсивностей. Из полученных спектров выделены следующие закономерности. Четкой зависимости соотношения интенсивностей линий $D$ и $G$ от дозы для гладких участков имплантированной поверхности не просматривается: доля алмазоподобной фазы вне микровыступов составляет 60-65\%. При максимальной дозе наблюдаются изменение соотношения концентраций связей $s p^{3}$ и $s p^{2}$ в пользу первых и признаки кристаллизации в областях

Письма в ЖТФ, 2017, том 43, вып. 24 
Электрофизические характеристики поверхностно-структурированных кремниевых пластин $p$-типа проводимости после глубинной и поверхностной высокодозных имплантаций ионов углерода

\begin{tabular}{c|c|c|c|c|c|c}
\hline $\mathrm{Z}^{17} \mathrm{~cm}^{-2}$ & $\begin{array}{c}\text { Энергия } \\
\text { ионов, } \\
\mathrm{keV}\end{array}$ & $\begin{array}{c}\text { Порог } \\
\text { авто- } \\
\text { эмиссии, } \\
\mathrm{V} / \mu \mathrm{m}\end{array}$ & $\begin{array}{c}\text { Макси- } \\
\text { мальная } \\
\text { плотность } \\
\text { тока, } \\
\mathrm{mA} / \mathrm{cm}^{2}\end{array}$ & $\begin{array}{c}\text { Высота } \\
\text { выступов, } \\
\mathrm{nm}\end{array}$ & $\begin{array}{c}\text { Поверх- } \\
\text { ностная } \\
\text { плотность } \\
\text { выступов, } \\
10^{10} \mathrm{~cm}^{-2}\end{array}$ & $\begin{array}{c}\text { Удельная } \\
\text { элекропро- } \\
\text { водность }\end{array}$ \\
\hline 10 & 80 & 80 & 28.6 & 6.4 & 4.9 & $91 \mathrm{mS} \cdot \square$ \\
$10+5$ & $80+30$ & 63 & 28.6 & 7.4 & 5.8 & $0.7 \mu \mathrm{S} \cdot \square$
\end{tabular}

микровыступов рельефа. Это выражается в обострении линий $D$ и $G$, которое свидетельствует об упорядочении структуры соответствующих фаз. Дополнительная имплантация $\mathrm{C}^{+} \mathrm{c}$ низкой энергией приводит к разупорядочению структуры.

В таблице приведены морфологические и автоэмиссионные характеристики, а также удельная электропроводность поверхностноструктурированных кремниевых пластин $p$-типа проводимости после глубинной и поверхностной высокодозных имплантаций ионов углерода. Из анализа данных таблицы видно, что дополнительная низкоэнергетическая имплантация ионов углерода в поверхностноструктурированные пластины кремния уменьшает пороги автоэмиссии. Максимальные плотности автоэмиссионных токов не изменяются. Удельная поверхностная электропроводность пластин после дополнительной низкоэнергетической имплантации ионов углерода уменьшается более чем на пять порядков. Высоты и поверхностные плотности выступов после дополнительной имплантации увеличиваются.

Полученные экспериментальные результаты могут быть интерпретированы следующим образом. Характерными свойствами высокодозной ионной имплантации наряду с возможностью управления профилем распределения внедренных ионов по глубине подложки являются формирование в мишени дефектов, распыление поверхностных атомов и ранее имплантированных ионов примеси, а также вторичная электронная эмиссия, при которой ионы выбивают из мишени электроны с малой энергией. Кроме того, особенностью ионного облучения, имеющей 


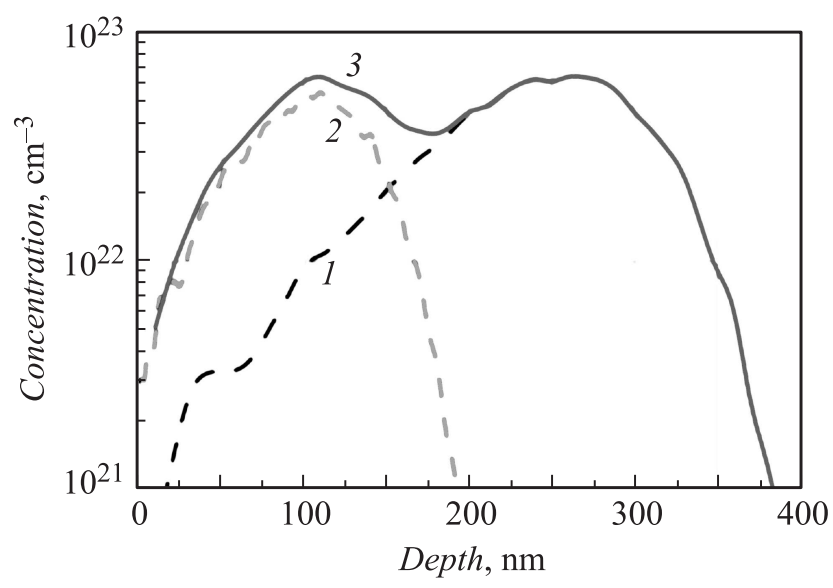

Рис. 3. Расчетные распределения в $\mathrm{Si}$ ионов $\mathrm{C}^{+}$, имплантированных с различными энергиями и дозами: $1-80 \mathrm{keV}$ при дозе $1 \cdot 10^{18} \mathrm{~cm}^{-2}, 2-30 \mathrm{keV}$ при дозе $5 \cdot 10^{17} \mathrm{~cm}^{-2}, 3-$ суммарный профиль распределения без учета ионного распыления.

важное значение для работы выхода электронов, является возможность формирования на поверхности мишени положительного заряда [4].

На рис. 3 приведены результаты компьютерного расчета профилей распределения внедренной примеси по глубине кремниевой мишени при высокодозной ступенчатой имплантации ионов углерода. Видно, что с увеличением энергии ионов глубина модифицированного слоя увеличивается. При этом возрастает „завал“ (уменьшение) концентрации дефектов у поверхности. Согласно оценкам, при энергии ионов углерода $80 \mathrm{keV}$ глубина их сосредоточения в приповерхностном слое кристаллов кремния составляет (без учета распыления) $350-400 \mathrm{~nm}$. Концентрация внедренных атомов углерода на этом расстоянии от поверхности при дозе $1 \cdot 10^{18} \mathrm{~cm}^{-2}$ составляет $\sim 6.4 \cdot 10^{22} \mathrm{~cm}^{-3}$. Этого достаточно для формирования углеродных фаз, в том числе стехиометрического карбида кремния $\mathrm{SiC}$ [5] (концентрация атомов в кристалле $\mathrm{Si}$ составляет $5 \cdot 10^{22} \mathrm{~cm}^{-3}$ ). Распределение радиационных дефектов в мишени повторяет распределение внедренных ионов примеси с тем отличием, что спад их концентрации по направлению к поверхности

Письма в ЖТФ, 2017, том 43, вып. 24 
происходит более медленно. Образующийся при энергии ионов $80 \mathrm{keV}$ в глубине аморфный кремний, а также $\mathrm{SiC}$ и $s p^{3}$-диэлектрические фазы увеличивают сопротивление во внутренних слоях пластин кремния. Это предотвращает переход к взрывной автоэмиссии и способствует обнаруженному увеличению более чем на два порядка максимальной плотности автоэмиссионных токов после высокодозной ионной имплантации углерода по сравнению с таковой для необлученных кристаллов кремния.

Дополнительная низкоэнергетическая имплантация позволяет приблизить максимум концентрации имплантированного углерода и возникающих дефектов к поверхности кристаллов до 80-100 nm (рис. 3, кривая 2). Кроме того, при учете ионного распыления приповерхностных слоев при дозах $5 \cdot 10^{17}$ и $1 \cdot 10^{18} \mathrm{~cm}^{-2}$, толщины которых, согласно оценкам, составляют 40 и $100 \mathrm{~nm}$ соответственно, должно обеспечиваться более равномерное распределение углеродных фаз по глубине образца и практически полное отсутствие „завала“ концентрации точечных дефектов у поверхности. При высокодозной ионной имплантации углерода в пластины кремния $p$-типа такими точечными дефектами в первую очередь становятся междоузельные атомы бора, которые первоначально находились в узлах кристаллической решетки кремния. Это обусловлено близкими значениями масс атомов бора и углерода. Благодаря этому коэффициент аккомодации, характеризующий эффективность передачи энергии ускоренного иона углерода атому бора, близок к единице. При этом выбитые из узлов кристаллической решетки кремния электрически активные атомы бора замещаются электрически нейтральной для кремния примесью углерода. Результатом этого являются дальнейшее развитие морфологии поверхности, которое выражается в увеличении высоты и поверхностной плотности выступов, резкое уменьшение удельной электропроводности структурированной поверхности кремния, которая приближается к собственной электропроводности полупроводника, а также возникновение в поверхностном слое положительного заряда, связанного с отсутствием электрона у имплантированного иона углерода. Образующийся таким образом положительный заряд на поверхности уменьшает работу выхода электронов и способствует тем самым уменьшению порога начала автоэмиссии (см. таблицу). Кроме того, за счет дезактивирования атомов бора в кристаллической решетке приповерхностной области кремния уровень Ферми в этой области смещается в сторону дна

Письма в ЖТФ, 2017, том 43, вып. 24 
зоны проводимости. Это приводит к обогащению (по сравнению с необлученным кремнием) приповерхностной области электронами. Благодаря этому, несмотря на уменьшение удельной электропроводности приповерхностной области, максимальные плотности автоэмиссионных токов на поверхностно-структурированных пластинах кремния $p$-типа практически не изменяются.

Ступенчатая ионная имплантация атомов углерода в поверхностноструктурированные с использованием нелитографических углеродных масочных покрытий пластины кремния $p$-типа позволяет уменьшить пороги начала автоэмиссии и увеличить плотности максимальных автоэмиссионных токов по сравнению с характерными для эмиттерных решеток, изготовленных с использованием традиционных микротехнологий, более чем на два порядка.

Исследование выполнено за счет гранта Российского научного фонда (проект № 16-19-10033).

\section{Список литературы}

[1] Velásquez-García L.F., Guerrera S., Niu Y., Akinwande A.I. // IEEE Trans. Electron Dev. 2011. V. 58. Iss. 6. P. 1783-1791.

[2] Гуляев Ю.В., Абаньшин Н.П., Горфинкель Б.И., Морев С.П., Резчиков А.Ф., Синицын Н.И., Якунин А.Н. // Письма в ЖТФ. 2013. Т. 39. В. 11. С. 63-70.

[3] Яфаров Р.К., Шаныгин В.Я. // ФТП. 2017. Т. 51. В. 4. С. 558-562.

[4] Технология СБИС / Под ред. С. Зи. Пер. с англ. М.: Мир, 1986. Кн. 1.404 с.

[5] Нусупов К.Х., Бейсенханов Н.Б., Валитова И.В., Дмитриева Е.А., Жумагалиулы Д., Шиленко Е.А. // ФТТ. 2006. Т. 48. В. 7. С. 1187-1199.

Письма в ЖТФ, 2017, том 43, вып. 24 